\title{
Comparação entre membrana amniótica com e sem epitélio como substrato para cultura de células epiteliais do limbo ex vivo
}

\author{
Comparison between amniotic membrane with and without epithelium as a support \\ for human limbal epithelial cells cultured ex vivo
}

Joyce Luciana Covre ${ }^{1}$, Renata Ruoco loureiro ${ }^{1}$, Priscila Cardoso Cristovam $^{1}$, José Reinaldo da Silva Ricardo ${ }^{2}$,

Edna Freymuller Haapalainen ${ }^{3}$, José Álvaro Pereira Gomes ${ }^{4}$

\begin{abstract}
RESUMO
Objetivo: Avaliar a eficácia e aspecto estrutural de células límbicas epiteliais humanas cultivadas sobre membrana amniótica (MA) com e sem epitélio.

Métodos: As culturas límbicas foram obtidas a partir de rima corneoescleral remanescentes de transplantes de córnea de 6 diferentes doadores. Cada explante fo cultivado em três diferentes grupos: MA desepitelizada por tripsina (Grupo 1), MA com epitélio íntegro (Grupo 2) e controle (Grupo 3). A migração epitelial foi avaliada por microscopia de contraste de fase. Após 15 dias, as células cultivadas sobre MA foram submetidas à microscopia eletrônica para avaliar migração e adesão epitelial. Resultados: Todas as células do grupo controle cresceram até atingir confluência. Somente uma das culturas em membrana amniótica desepitelizada não apresentou crescimento epitelial. O crescimento de células epiteliais sobre membrana amniótica epitelizada foi observada em apenas uma cultura.

Conclusão: Baseando-se nestes achados, o uso de membrana amniótica desepitelizada aparenta ser o melhor substrato para migração e adesão epitelial comparando com membrana amniótica epitelizada. Remover o epitélio da membrana amniótica demonstra ser um importante passo para estabelecer culturas de células sobre membrana amniótica.
\end{abstract}

Descritores: Células epiteliais; Técnicas de cultura de células; Membrana amniótica; Células-tronco; Limbo da córnea; Córnea/citologia; Adesão celular; Estudo comparativo

\begin{abstract}
Purpose: To evaluate the efficacy and ultrastructural aspects of human limbal epithelial cells cultured on amniotic membrane (AM) with and without epithelium.

Methods: Limbal epithelial cell cultures were established from cadaveric corneo-scleral rim explants derived from 6 different donors. The explants from each donor were placed under 3 different groups: on human preserved AM with epithelium (Group 1), AM deepithelialized with trypsin (Group 2) and control (Group 3). The epithelial cell migration was evaluated under phase contrast microscopy. After 15 days, the amniotic membrane with cells cultures were removed and submitted to scanning and transmission electron microscopy to check for epithelial migration and adhesion.

Results: All epithelial cell cultures from the controls grew over the botton of the culture plate wells until reaching confluence. Epithelial cultures grew over all but one denuded amniotic membrane. In the group amniotic membrane with epithelium, epithelial cell growing was observed only in 1 well.

Conclusions: Using this model, denuded amniotic membrane appeared to be the best substrate for epithelial cell migration and adhesion comparing to amniotic membrane with epithelium. Removal of amniotic membrane epithelial seems to be an important step for establishing limbal epithelial cell culture on amniotic membrane.

Keywords: Epithelial cells; Cell culture techniques; Amniotic membrane; Stem cells; Limbus corneae; Cornea/cytology; Cell adhesion; Comparative study
\end{abstract}

\section{INTRODUÇÃO}

O epitélio corneano tem uma rápida capacidade de regeneração que depende da presença das células-tronco (CTs) localizadas na camada basal do limbo. Esse epitélio consiste de CTs, células amplificadoras transitórias (CAT), células pós-mitóticas e células diferenciadas. Tanto as CAT quanto as CTs têm a capacidade de se multiplicarem. No entanto, enquanto as CTs têm alto potencial proliferativo, as CAT têm capacidade limitada de divisão celular $r^{(1-2)}$.

Muitas condições patológicas podem levar à deficiência de células-tronco do limbo (DCTL), como queimadura ocular química ou térmica, síndrome de Stevens-Johnson, ceratopatia induzida por lente de contato, aniridia, entre outras. Esse processo é caracterizado pela invasão da superfície corneana pelo epitélio conjuntival, inflamação crônica, defeitos epiteliais persistentes, cicatrização estromal e neovascularização, produzindo diminuição da acuidade visual e fotofobia ${ }^{(3-4)}$

O tratamento atual da DCTL unilateral é o transplante autólogo de limbo. Nos casos bilaterais é necessária uma fonte externa de CTs. Na eventualidade de não haver doador vivo compatível, a alternativa é o transplante de limbo de doador vivo não compatível ou de cadáver sob imunossupressão(5-10). Nos casos de deficiência límbica parcial, o transplante de membrana amniótica (TMA) é uma boa opção para prover a proliferação das CTs límbicas remanescentes $^{(11-13)}$. Recentemente, uma nova opção para o tratamento de pa-
Submitted for publication: September 16, 2010

Accepted for publication: February 28, 2011

Study carried out at the Universidade Federal de São Paulo - UNIFESP - São Paulo (SP), Brasil.

Bachelor of biomedicine, Centro Avançado de Superfície Ocular - CASO, Instituto da Visão, Departamento de Oftalmologia, Universidade Federal de São Paulo - UNIFESP - São Paulo (SP), Brasil. Physician, Departamento de Oftalmologia, Universidade Federal de São Paulo - UNIFESP - São Paulo (SP), Brasil.

Professor, Centro de Microscopia Eletrônica, Universidade Federal de São Paulo - UNIFESP - São Paulo (SP), Brasil.

Professor, Departamento de Oftalmologia, Universidade Federal de São Paulo - UNIFESP - São Paulo (SP), Brasil.
Funding: This study was supported by FAPESP (Fundação de Amparo a Pesquisa do Estado de São Paulo, SP, Brazil).

Disclosure of potential conflicts of interest: J.L.Covre, None; R.R. Loureiro, None; P.C.Cristovam, None; J.R.S.Ricardo, None, E.F Haapalainen, None; J.A.P.Gomes, Consultant (Alcon, Allergan, Bausch \& Lomb), Speaker (Alcon, Allergan, Bausch \& Lomb).

Correspondence address: José Álvaro Pereira Gomes. Rua Sabará, 566 - Cj. 43 - São Paulo - SP 01239-010 - Brazil - E-mail: japgomes@uol.com.br

Editorial Note: After completing the confidential analysis of the manuscript, ABO discloses, with his agreement, the name Dr. Marcelo Vieira Neto as a reviewer. We thank his effort and expertise in participating in this process. 
cientes com DCTL é o transplante de células-tronco límbicas cultivadas ex vivo ${ }^{(14-18)}$. O objetivo do transplante dessas células é restaurar um epitélio corneano transparente. No entanto, o exato mecanismo de ação de como isso ocorre ainda não foi determinado.

O substrato mais usado no cultivo dessas células é a membrana amniótica (MA), que preserva o potencial das CTs límbicas e mantém suas propriedades in vivo ${ }^{(15-21)}$. Existem variações na forma de cultivo de CTs límbicas na MA que podem influenciar as características das células cultivadas. Entre elas, a presença ou ausência de epitélio é uma das principais diferenças.

Para determinar qual o método ideal para cultivar células epiteliais límbicas expandidas ex vivo, objetivou-se comparar o efeito da presença do epitélio amniótico na proliferação e morfologia das células cultivadas.

\section{MÉTODOS}

\section{Obtenção e preparo da membrana amniótica}

A obtenção e o processamento da MA foram realizados de acordo com as normas do protocolo aprovado pela Comissão de Ética da UNIFESP/EPM. Essas normas baseiam-se no protocolo proposto por Kim e Tseng (1995)(22), seguindo as premissas impostas pela Food and Drug Administration (FDA) e The American Association of the Tissue Banking (AATB).

A MA foi obtida a partir das placentas provenientes de cesáreas eletivas realizadas no Hospital Maternidade Amparo Maternal após consentimento assinado pelas gestantes. Todas essas pacientes tiveram exames sorológicos negativos para HIV-1, Hepatite B, Hepatite C e sífilis (VDRL), que foram reconfirmados pela realização de sorologia do sangue do cordão umbilical após o parto.

Após a obtenção da placenta no centro cirúrgico obstétrico, procedeu-se à sua lavagem com o uso de solução fisiológica 0,9\% em ambiente estéril. Posteriormente, o âmnio foi separado do córion com a utilização de tesoura e pinça estéreis e estendido sobre um filtro de nitrocelulose estéril (Millipore, Bedfort, MA, EUA) com a face epitelial para cima. A membrana e o filtro foram lavados com solução tampão fosfato contendo $1000 \mathrm{U} / \mathrm{ml}$ de penicilina, $20 \mathrm{mcg} / \mathrm{ml}$ de estreptomicina e $2,5 \mathrm{mcg} / \mathrm{ml}$ de Anfotericina B (Ophthalmos, São Paulo), cortados em fragmentos de aproximadamente $3 \times 3 \mathrm{~cm}$, colocados em um recipiente estéril com o meio TC-199: glicerol 1:1 (Ophthalmos, São Paulo) e congelados a $-8^{\circ} \mathrm{C}$. Amostras de cada membrana obtida foram enviadas para estudo histopatológico e microbiológico (bacterioscopia e cultura). O tempo máximo de utilização da membrana foi de 3 meses após o congelamento.

\section{Cultura de células epiteliais do limbo sobre a MEMBRANA AMNIÓTICA}

Biópsias de limbo $(n=6)$ de aproximadamente $2 \mathrm{~mm} \times 4 \mathrm{~mm}$ foram colocadas sobre MA com e sem epitélio e na placa controle (placa de cultura com 6 poços de $35 \mathrm{~mm}$ - TTP, Switzerland). Foi adicionado meio de cultura contendo DMEM e Ham's F12 (na proporção de 1:1; Invitrogen) suplementado com 10\% de soro bovino fetal, $2 \mathrm{ng} / \mathrm{mL}$ de EGF (epidermal growth factor) (Sigma-Aldrich, St. Louis, MO), 0,1 $\mu \mathrm{g} / \mathrm{mL}$ de toxina colérica (Sigma-Aldrich, St. Louis, $\mathrm{MO}$ ), $1 \mathrm{\mu g} / \mathrm{mL}$ de insulina recombinante humana (Sigma-Aldrich, St. Louis, MO), $5 \mu \mathrm{g} / \mathrm{mL}$ de hidrocortisona, penicilina, estreptomicina e anfotericina B (Sigma-Aldrich, St. Louis, MO). O meio de cultura foi trocado a cada dois dias e as culturas foram mantidas por duas semanas. Todos os parâmetros acima descritos foram utilizados de forma similar nos grupos analisados.

Foram coletados 6 fragmentos de MA medindo cerca de $3 \times 3 \mathrm{~cm}$. Estes foram divididos em 3 grupos:

- Grupo 1: MA desepitelizada por tripsina $(2 \mathrm{mg} / \mathrm{ml}$ de tripsina a 1:250 a $37^{\circ} \mathrm{C}$ por 2 horas, seguida por fricção mecânica para remover as células epiteliais amnióticas) + explante límbico.
- Grupo 2: MA com epitélio íntegro + explante límbico.

- Grupo 3 (Grupo controle): placa de cultura + explante límbico.

\section{Microscópio de CONTRASte de FASE E AVALIAÇão de MigRAÇão}

Todas as culturas foram avaliadas por microscopia de contraste de fase diariamente e a avaliação da migração celular e características morfológicas foi feita a cada dois dias por duas semanas. A área de migração epitelial sobre a membrana amniótica foi determinada durante a mudança dos meios. A margem do epitélio foi marcada externamente com uma caneta de ponta porosa, delimitando a área de crescimento celular. Posteriormente, foi colocada uma folha de papel milimetrado transparente sob a placa para contagem em $\mathrm{mm}^{2}$ da área previamente delimitada (Figura 1/Figura 2).

\section{Microscopia Eletrônica de transmissão (MET)}

Duas amostras de cada grupo (total de 4) foram submetidas à análise por microscopia eletrônica de transmissão para avaliar as características ultraestruturais. A MA foi lavado em tampão cacodilato, $(0,2 \mathrm{M}, \mathrm{pH} 7,2)$ para retirar o meio de preservação e foi colocado formaldeído 2\%, glutaraldeído 2,5\%, CaCl 25 mg/ml (Sigma Chemical, St. Louis, MO, EUA) por 2 horas em temperatura ambiente. Após retirado o fixador, o tecido foi deixado em tampão cacodilato (EM Sciences, Philadelphia, PA, EUA) por $24 \mathrm{~h}$ a $4^{\circ} \mathrm{C}$. Iniciou-se a in-

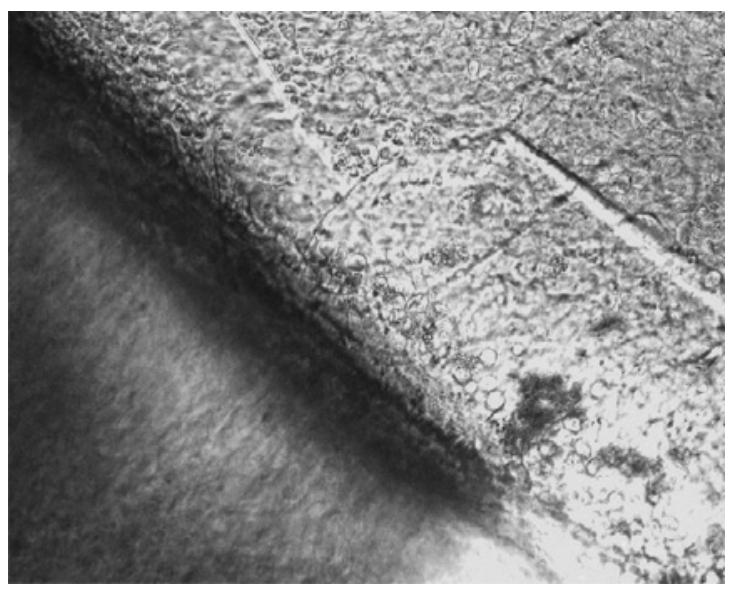

Figura 1. Cultura de limbo sobre membrana epitelizada (microscopia invertida 40x).

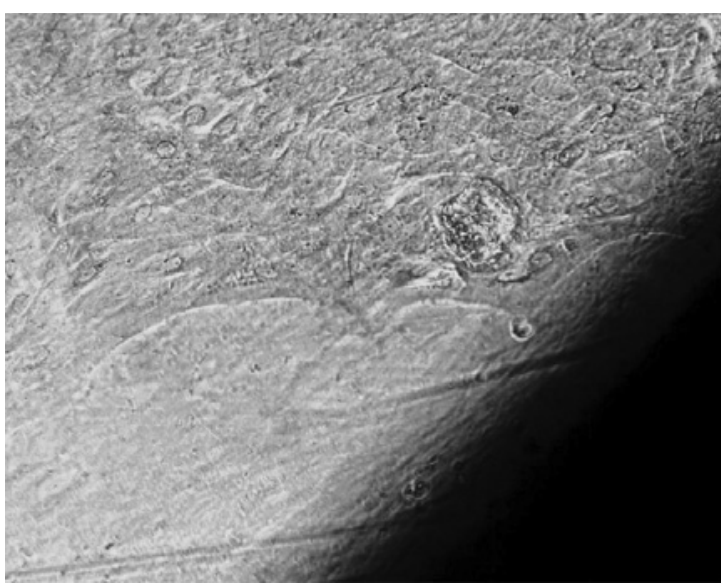

Figura 2. Cultura de limbo sobre membrana desepitelizada (microscopia invertida 40x). 
clusão colocando o tecido em solução de ósmio a 2\% (EM Sciences, Philadelphia, PA, EUA) por 1 hora em temperatura ambiente. 0 tecido foi lavado 2 vezes por 1 minuto, em água bidestilada e foi colocado em solução de acetato de uranila (uranila 0,5\% e sacarose 13,3\%) (EM Sciences, Philadelphia, PA, EUA) por 30 minutos. Após duas lavagens em água bidestilada, o tecido foi desidratado em etanol $70 \%$ por 30 minutos, etanol $90 \%$ por 30 minutos e etano $100 \%$ por 40 minutos. Colocou-se o tecido em óxido de propileno (EM Sciences, Philadelphia, PA, EUA) por 40 minutos, e, depois, em uma mistura de 2 partes de óxido de propileno para 1 parte de resina Araldite (EM Sciences, Philadelphia, PA, EUA) por 4 horas em agitador orbital. A resina foi desprezada e colocada no tecido na mistura de 1 parte de óxido de propileno para 1 parte de Araldite, que foi deixado sem tampa, por 16 a 18 horas, em agitador orbital. O tubo contendo tecido foi transferido em resina para câmara de vácuo por 4 a 5 horas e, depois, cada peça do tecido foi colocada em blocos próprios para MET. Cada peça de tecido foi polimerizada a $60^{\circ} \mathrm{C}$ por 48 horas e seccionada em cortes semifinos $(0,3$ a 0,5 $\mu \mathrm{m})$ e ultrafinos (70 a $90 \mathrm{~nm}$ ) para observação microscópica. (Jeol JEM 1200 EXII)

\section{Microscopia eletrônica de VarRedura (MEV)}

Seis amostras de cada grupo (total de 12) foram analisadas pela microscopia eletrônica de varredura. O tecido foi lavado em tampão cacodilato $(0,2 \mathrm{M}, \mathrm{pH} 7,2)$ para retirar o meio de preservação e foi colocado em fixador formaldeído 2\%, glutaraldeído 2,5\%, CaCl $25 \mathrm{mg} / \mathrm{ml}$ por 2 horas em temperatura ambiente. Após retirar o fixador e o tecido foi deixado em tampão cacodilato por 24 horas a $4^{\circ} \mathrm{C}$. Iniciou-se a inclusão colocando o tecido em solução de ósmio a $1 \%$ por 1 hora em temperatura ambiente. $O$ tecido foi lavado por 30 minutos (3 trocas de 10 minutos cada) em tampão cacodilato 0,1 M e colocado em solução de ácido tânico a 1\% por 30 minutos. Após 2 lavagens com água bidestilada, colocou-se o tecido em solução de ósmio a 1\% por 30 minutos. O tecido foi lavado em água bidestilada por 15 minutos e desidratado em concentrações crescentes de etanol (50, 70, 90 e 100\%, 20 minutos cada). Com o material em etanol a 100\%, foi colocado em aparelho de ponto crítico (Balzers, modelo CPD-030). O material foi transferido para o "stub" metálico e submetido ao processo de metalização com ouro no aparelho de "sputtering" (Balzers, modelo SCD-050). Posteriormente, foi feita a análise por microscopia eletrônica de varredura. (Jeol JSM - 5300).

\section{Análise estatística}

Os testes estatísticos que foram utilizados para comparar as variáveis entre os três grupos de estudo são: qui-quadrado $\chi^{2}$ com correção de Yates para proporções (Teste de Fisher), teste t de Student e análise de variância (SPSS ver.12, SPSS Inc. Chicago, IL EUA).

Probabilidades de menos de $5 \%$ foram consideradas estatisticamente significativas. Para os testes repetidos, utilizou-se a correção de Bonferroni para corrigir erros do tipo I acumulativo.

\section{RESULTADOS}

\section{Morfologia e AVALIAÇÃo dA MIGRAÇÃo}

A expansão epitelial no Grupo 1 (MA desepitelizada) ocorreu em 5/6 (83,33\%) dos explantes cultivados. O epitélio formado apresentou uma camada de células bem-estratificada. Por outro lado, no Grupo 2 (MA intacta), apenas 1/6 (16,67\%) dos explantes apresentou expansão celular, com a formação de um epitélio com uma ou duas camadas de células. No Grupo 3 (placa controle), houve expansão em $6 / 6$ (100\%) dos casos. Houve diferença estatisticamente significativa em relação ao crescimento celular em membranas amnióticas com epitélio e sem epitélio ( $P=0,0052)$ (Tabela 1).
Tabela 1. Comparação do crescimento de células epiteliais do limbo sobre membrana amniótica epitelizada e desepitelizada

\begin{tabular}{lccc}
\hline & $\begin{array}{c}\text { Grupo 1 } \\
\text { (MA sem epitélio) } \\
\text { N (\%) }\end{array}$ & $\begin{array}{c}\text { Grupo 2 } \\
\text { (MA com epitélio) } \\
\text { N (\%) }\end{array}$ & $\begin{array}{c}\text { Grupo 3 } \\
\text { (Placa controle) } \\
\text { N (\%) }\end{array}$ \\
\hline Crescimento & $5(83,33 \%)$ & $1(16,67 \%)$ & $6(100 \%)$ \\
Sem crescimento & $1(16,67 \%)$ & $5(83,33 \%)$ & $0(0 \%)$ \\
Total & $6(100,00 \%)$ & $6(100,00 \%)$ & $6(100 \%)$ \\
\hline
\end{tabular}

Odds ratio (membrana amniótica sem epitélio x com epitélio) =25,0000

$\mathrm{Cl} 95 \%=1,2002$ a 520,7629

Teste deFisher (membrana amniótica sem epitélio x com epitélio) $p=0,080087$ Qui-quadrado; $P=0,0052$

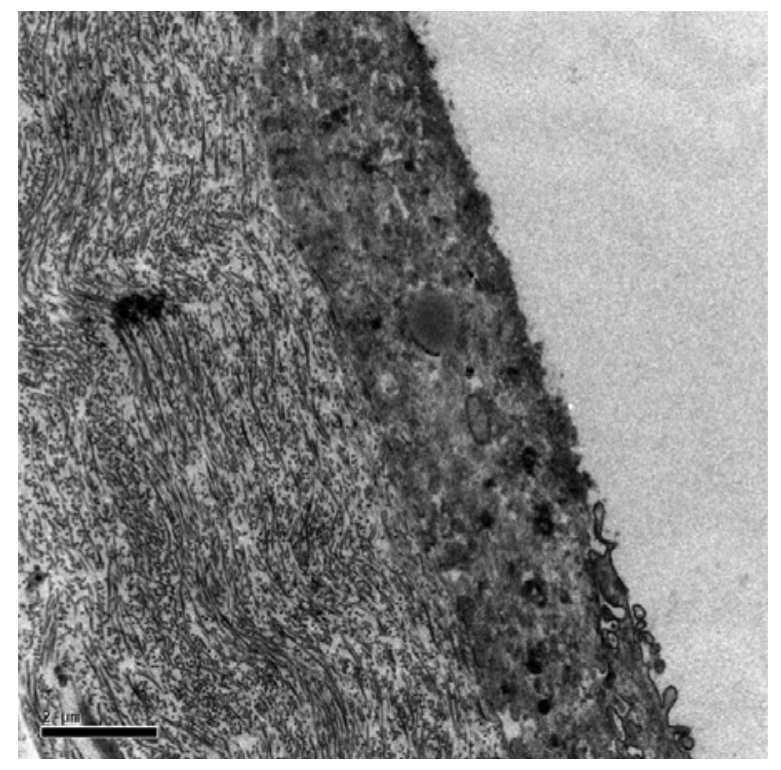

Figura 3. MET evidenciando epitélio do limbo monoestratificado irregulare com sinais de alterações estruturais intracelulares sobre MA epitelizada.

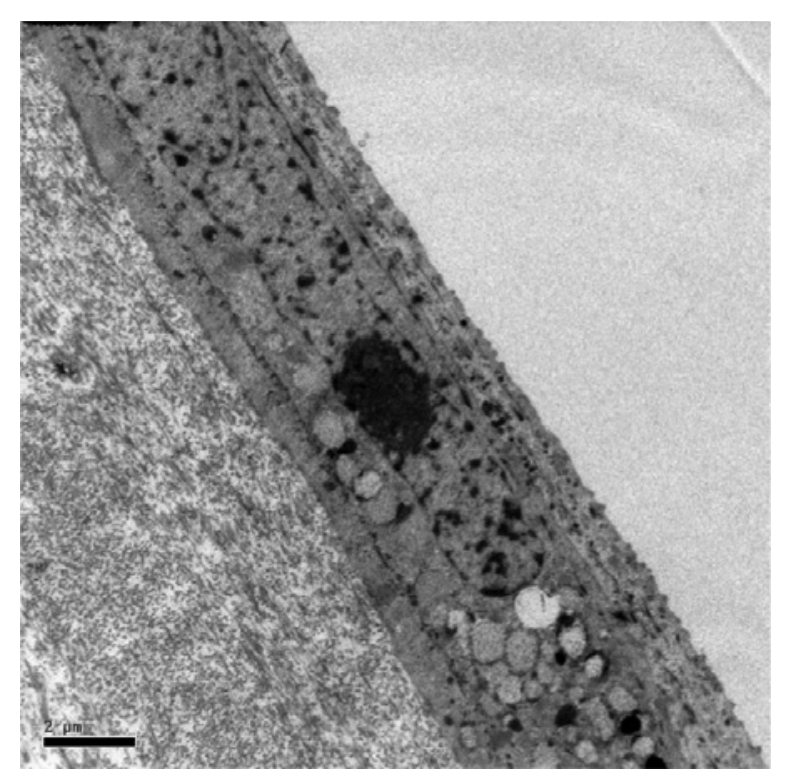

Figura 4. MET de células do limbo demonstrando epitélio integro estratificado diferenciado com 4 a 5 camadas sobre MA desepitelizada. 


\section{Microscopia Eletrônica de tRANSMISSÃo}

As células do Grupo 1 (MA desepitelizada) as células apresentaram-se bem-estratificadas e diferenciadas com 4 a 5 camadas. Foi observado que as células basais encontravam-se bem aderidas a MA com a formação de hemidesmossomos e a produção de material de membrana basal (Figura 3/Figura 4). Por outro lado, no Grupo 2 (MA intacta), o epitélio monoestratificado apresentava grandes espaços adjacentes entre as células. Estas células não estavam bem aderidas à membrana basal e apresentavam pouca evidência de material de membrana basal. Os espaços entre as células eram largos e com poucos desmossomos.

\section{Microscopia eletrônica de VARRedura}

As células epiteliais do limbo no Grupo 2 (cultivadas na MA desepitelizada) apresentou-se densamente compactado com bordas nítidas. Foram observados microvilos apicais pequenos e regulares em aparência muito semelhante ao epitélio corneano normal. Por outro lado, o epitélio do Grupo 1 (cultivado na MA intacta) apresentaram bordas pouco nítidas. A superfície celular estava coberta por microvilos anormalmente longos. Em algumas áreas, as células epiteliais cresceram sobre o epitélio amniótico com pobre formação de estruturas de adesão. As células epiteliais adjacentes não estavam bem aderidas umas às outras e existiam espaços intercelulares proeminentes.

\section{DISCUSSÃO}

Este estudo avaliou a diferença de morfologia e proliferação do epitélio límbico cultivado ex vivo na MA com e sem epitélio. A remoção completa do epitélio da MA resultou na formação de um epitélio confluente em 83,3\% dos casos, enquanto o cultivo destas mesmas células na MA com epitélio resultou na expansão celular e confluência em apenas 16\% dos explantes. Isto sugere que a remoção do epitélio da MA no cultivo celular facilita a expansão e a formação de um epitélio bem formado.

Estes achados são consistentes com os relatados por Koizumi et al. ${ }^{(23)}$ que compararam o cultivo de células do limbo na MA intacta e desepitelizada e encontraram epitélio bem-estratificado e diferenciado nas culturas em MA desepitelizadas, enquanto a MA intacta resultou na formação de epitélio monocelular apenas em algumas áreas. Os autores concluíram que a remoção do epitélio resultaria em epitélio mais bem formado e com características meIhores para serem transplantados.

Por outro lado, Grueterich et al. ${ }^{(18)}$, mostraram que em culturas sobre a MA intacta as células epiteliais límbicas expandidas apresentavam características de CTs como conexina 43 - e CK3 -. Porém, tais resultados diferem de outro estudo feito por Du et al. ${ }^{(24)}$, no qual as células cultivadas sobre a MA epitelizadas não apresentaram as mesmas características descritas por Grueterich et al. ${ }^{(18)}$.

Existe uma discussão entre transplantar clinicamente epitélio cultivado com um maior ou menor estado de diferenciação. O epitélio mais diferenciado tem a vantagem de formar estruturas de adesão mais bem formadas, o que aumenta a segurança do procedimento, embora com menor expressão de marcadores de CTs, o que pode comprometer sua viabilidade a longo prazo. $O$ epitélio menos diferenciado expressa maior quantidade de marcadores de CTs, mas tem a desvantagem de formar um tecido com poucas estruturas de adesão, o que pode levar a deslocamento e perda do tecido. Contudo, de acordo com Sangwan et al., um tecido com epitélio monoestratificado continua a proliferar in vivo e produz epitélio estratificado após o transplante ${ }^{(20)}$.
Como o objetivo final do cultivo das células epiteliais do limbo é o transplante em pacientes com DTCTL e diante da dificuldade de cultivar o tecido em MA epitelizada, nós sugerimos que o cultivo das células epiteliais límbicas seja feito na MA desepitelizada, o qual possibilita o crescimento de um epitélio mais semelhante ao epitélio corneano saudável e aumenta a segurança do transplante ex vivo.

\section{REFERÊNCIAS}

1. Schermer A, Galvin S, Sun TT. Differentiation-related expression of a major 64K corneal keratin in vivo and in culture suggests limbal location of corneal epithelial stem cells. J Cell Biol. 1986;103(1):49-62.

2. Pellegrini G, Golisano O, Paterna P, Lambiase A, Bonini S, Rama P, et al. Location and clonal analysis of stem cells and their differentiated progeny in the human ocular surface. J Cell Biol. 1999;145(4):769-82

3. Tseng SC. Concept and application of limbal stem cells. Eye (Lond). 1989;3(Pt 2):141-57.

4. Tseng SC. Regulation and clinical implications of corneal epithelial stem cells. Mol Biol Rep. 1996;23(1):47-58.

5. Tan DT, Ficker LA, Buckley RJ. Limbal transplantation. Ophthalmology. 1996;103(1):29-36.

6. Tsai RJ, Tseng SC. Human allograft limbal transplantation for corneal surface reconstruction. Cornea. 1994;13(5):389-400.

7. Tsubota K, Saito H, Shinozaki N, Shimazaki J. Reconstruction of the corneal epithelium by limbal allograft transplantation for severe ocular surface disorders. Ophthalmology. 1995; 102(10):1486-96.

8. Dua HS, Azuara-Blanco A. Allo-limbal transplantation in patients with limbal stem cell deficiency. Br J Ophthalmol. 1999;83(4):414-9. Comment in: Br J Ophthalmol. 1999;83(12): 1409. Br J Ophthalmol. 1999:83(12):1409-10.

9. Kwitko S, Marinho DR, Barcaro S, Bocaccio F, Rymer S, Fernandes S, et al. Allograft conjunctival transplantation for bilateral ocular surface disorders. Ophthalmology. 1995; 102(7):1020-5.

10. Kenyon KR, Rapoza PA. Limbal allograft transplantation for ocular surface disorders. Ophthalmology. 1995;102(Suppl):101-2.

11. Shimazaki J, Yang HY, Tsubota K. Amniotic membrane transplantation for ocular surface reconstruction in patients with chemical and thermal burns. Ophthalmology. 1997;104(12): 2068-76. Comment in: Ophthalmology. 2000;107(3):411-2.

12. Tseng SC, Prabhasawat P, Barton K, Gray T, Meller D. Amniotic membrane transplantation with or without limbal allografts for corneal surface reconstruction in patients with limbal stem cell deficiency. Arch Ophthalmol 1998;116(4):431-41.

13. Fukuda K, Chikama T, Nakamura M, Nishida T. Differential distribution of subchains of the basement membrane components type IV collagen and laminin among the amniotic membrane, cornea, and conjunctiva. Cornea. 1999; 18(1):73-9.

14. Pellegrini G, Traverso CE, Franzi AT, Zingirian M, Cancedda R, De Luca M. Long-term restoration of damaged corneal surfaces with autologous cultivated corneal epithelium. Lancet. 1997;349(9057):990-3. Comment in: Lancet. 1997;349(9064):1556.

15. Schwab IR, Reyes $M$, Isseroff RR. Successful transplantation of bioengineered tissue replacements in patients with ocular surface disease. Cornea. 2000;19(4):421-6.

16. Meller D, Pires RT, Tseng SC. Ex vivo preservation and expansion of human limbal epithelial stem cells on amniotic membrane cultures. Br J Ophthalmol. 2002;86(4):463-71.

17. Shimazaki J, Aiba M, Goto E, Kato N, Shimmura S, Tsubota K. Transplantation of human limbal epithelium cultivated on amniotic membrane for the treatment of severe ocular surface disorders. Ophthalmology. 2002; 109(7):1285-90.

18. Grueterich M, Espana E, Tseng SC. Connexin 43 expression and proliferation of human limbal epithelium on intact and denuded amniotic membrane. Invest Ophthalmol Vis Sci. 2002;43(1):63-71.

19. Schwab IR. Cultured corneal epithelia for ocular surface disease. Trans Am Ophthalmol Soc. 1999;97:891-986.

20. Sangwan VS, Vemuganti GK, Singh S, Balasubramanian D. Successful reconstruction of damaged ocular outer surface in humans using limbal and conjuctival stem cell culture methods. Biosci Rep. 2003;23(4):169-74. Erratum in: Biosci Rep. 2006;124(10):1483.

21. Sangwan VS, Matalia HP, Vemuganti GK, Fatima A, Ifthekar G, Singh S, et al. Clinical outcome of autologous cultivated limbal epithelium transplantation. Indian J Ophthalmol. 2006; 54(1):29-34.

22. Kim JC, Tseng SC. Transplantation of preserved human amniotic membrane for surface reconstruction in severely damaged rabbit corneas. Cornea. 1995;14(5):473-84.

23. Koizumi N, Rigby H, Fullwood NJ, Kawasaki S, Tanioka H, Koizumi K, et al. Comparison of intact and denuded amniotic membrane as a substrate for cell-suspension culture of human limbal epithelial cells. Graefes Arch Clin Exp Ophthalmol. 2007;245(1):123-34.

24. Du Y, Chen J, Funderburgh JL, Zhu X, Li L. Functional reconstruction of rabbit corneal epithelium by human limbal cells cultured on amniotic membrane. Mol Vis. 2003;9:635-43. 